\title{
Using the life-cycle model with value thinking for managing an industrial maintenance network
}

\author{
Tiina Sinkkonen*, Harri Kivimäki, Salla Marttonen, Diego Galar, Roberto \\ Villarejo and Timo Kärri
}

\begin{abstract}
The objective of this article is to create a general life-cycle model for maintenance decision making in different industries at the item level. The need for network-level tools will increase, as inter-organizational collaboration is emphasized more and more. Previous life-cycle models have mostly viewed the matter from the perspective of just one company, but our model takes the different members of maintenance networks into account. We have also integrated value thinking with life-cycle accounting, as it is crucial for companies to perceive which elements increase the value of each member in their network. The value-based lifecycle model introduced in this article has been mainly developed to support the future planning of maintenance operations. In addition, it can be designed how additional value can be reached through future maintenance and how this value can be equitably shared between the network partners.
\end{abstract}

Key words: Value, life cycle, maintenance, networks, model

\section{Introduction}

The importance of industrial maintenance has been emphasized during the last decades: it is no longer a mere cost item, but one of the mainstays of business. Market conditions have worsened lately, investments in production assets have decreased, and companies have focused more on their core functions. These changes have caused increasing restructuring, especially outsourcing, of maintenance in industrial companies. The main benefits pursued through outsourcing include for example cost savings, resource optimization, increased safety, and superior quality. However, 
despite the possible benefits of maintenance outsourcing, there are also some risks that can be increased when buying services from an outside service provider: for example losing the know-how of your personnel, facing general resistance to change, or high dependency on the service provider (Gómez et al., 2008; Kumar and Markeset, 2007).

The high number of maintenance outsourcings has been followed by increased inter-organizational collaboration and new collaborative networks as regards industrial maintenance. Thus there is a growing need for network-level tools to support decision making and maintenance management. In addition, to promote advantageous collaboration, it is crucial for companies to know the preferences of their network partners: companies may think they know what elements in maintenance services are the most important for their partners, but they can be wrong. Thus this information on the most important value-creating elements should be made explicit to advance win-win situations in networks.

We address the above-mentioned issues by introducing a novel tool for maintenance networks. Our objective is to create a general life-cycle model to support decision making in company networks as regards itemlevel maintenance. The research questions of the paper are the following:

- What kind of structure is needed for a life-cycle model that takes the perspectives of different maintenance network members into account?

- How can the concept of value be integrated into the life-cycle model?

- How can the results generated by the model be used in decision making?

Models of this kind have not been introduced in the academic literature before. Previous models (e.g. Jun and Kim, 2007; Waghmode and Sahasrabudhe, 2012) have mostly concerned the perspective of a single company. In our model the inspection is done from the perspectives of different members of a maintenance network: a maintenance customer (who buys maintenance services), a service provider (who provides maintenance services for the customer), and an equipment provider (who supplies equipment and some related maintenance services for the customer). The groundwork for the model has been done mostly with qualitative data (Sinkkonen et al., 2013B; Tynninen et al., 2012). Thus we consider it important that the model introduced in this paper can be tested with quantitative data, in other words with actual and estimated costs and 
Title

profits. The model guides the user in decreasing the costs (see e.g. Idhammar, 2009) and increasing the profits (see e.g. Gokiene, 2010; Knights et al., 2004) of maintenance services during the life cycle of the item at issue. The model is suitable for different kinds of production equipment, as well as for various industries.

After this introductory section, the theoretical framework for the model is discussed in section 2. Next, section 3 introduces the research design, including the modelling process and the research context. Section 4 addresses the value-based life-cycle model for maintenance networks, and explicates how the model has been validated in cooperation with the mining industry. The article finishes with conclusions in section 5.

\section{Theoretical framework of the model}

Life-cycle costing (LCC) hails from the 1960s when the United States Army started to use it to estimate their acquisition costs. This method has typically been used in construction industry and government investments. However, it is still not very familiar in the field of industrial companies (Korpi and Ala-Risku, 2008). Conventionally LCC has been seen as a tool for calculating the investment costs of the whole life-cycle period of an item. During the last years, different kinds of life-cycle models (LCM) have been developed for companies to plan the future and organize their operations in the long term, meaning better transparency of costs, activities, and their interaction (Lindholm and Suomala, 2007; Blanchard and Fabrycky, 1998).

Table 1 presents seven recent academic studies which discuss maintenance costs and LCMs. These academic studies have similar features as our lifecycle framework, but there are also some major differences. Most of the models still focus on different kinds of new or replacement investments (e.g. Navarro-Galera and Ortúzar Maturana, 2011), being usually very case-specific and thus suitable only for the item in question (Hochschorner and Noring, 2011). However, there is also an increased interest towards models connecting maintenance costs and life-cycle thinking (see e.g. Jun and Kim, 2007; Waghmode and Sahasrabudhe, 2012; Lad and Kulkarni, 2012). It should be noted that there are still very few models integrating value thinking with maintenance costs (Wang and $\mathrm{Xu}, 2009$ ). Also the life-cycle profits (LCP), e.g. minimizing downtime and failures, are mainly neglected in the previous models. 
Table 1. List of the LCC articles reviewed for this paper

\begin{tabular}{|c|c|c|c|}
\hline Authors & Year & Title of the article & Substance of the article \\
\hline Jun \& Kim & 2007 & $\begin{array}{l}\text { Life cycle cost modelling } \\
\text { for railway vehicle }\end{array}$ & $\begin{array}{l}\text { - A model that uses net present } \\
\text { value } \\
\text { - Maintenance costs are one of the } \\
\text { three cost categories }\end{array}$ \\
\hline Wang \& Xu & 2009 & $\begin{array}{l}\text { SVLC: Service value life } \\
\text { cycle model }\end{array}$ & $\begin{array}{l}\text { - An LCM for consumer services } \\
\text { - Main focus is on the quality of } \\
\text { the services }\end{array}$ \\
\hline $\begin{array}{l}\text { Navarro-Galera } \\
\text { \& Ortúzar } \\
\text { Maturana }\end{array}$ & 2011 & $\begin{array}{c}\text { Innovating in defence } \\
\text { policy through spending } \\
\text { efficiency: The life cycle } \\
\text { costing model }\end{array}$ & $\begin{array}{l}\text { - An LCM for defence costs and } \\
\text { economic growth } \\
\text { - Empirical study }\end{array}$ \\
\hline $\begin{array}{c}\text { Kayrbekova et } \\
\text { al. }\end{array}$ & 2011 & $\begin{array}{l}\text { Activity-based life cycle } \\
\text { cost analysis as an } \\
\text { alternative to } \\
\text { conventional LCC in } \\
\text { engineering design }\end{array}$ & $\begin{array}{l}\text { - Activity-based life cycle cost } \\
\text { analysis as an alternative to } \\
\text { conventional LCC }\end{array}$ \\
\hline $\begin{array}{l}\text { Hochschorner } \\
\text { \& Noring }\end{array}$ & 2011 & $\begin{array}{l}\text { Practitioners' use of life } \\
\text { cycle costing with } \\
\text { environmental costs - a } \\
\text { Swedish study }\end{array}$ & $\begin{array}{c}\text { - Using LCC as a part of decision } \\
\text { making } \\
\text { - Interview study }\end{array}$ \\
\hline $\begin{array}{l}\text { Waghmode \& } \\
\text { Sahasrabudhe }\end{array}$ & 2012 & $\begin{array}{l}\text { Modelling maintenance } \\
\text { and repair costs using } \\
\text { stochastic point processes } \\
\text { for life cycle costing of } \\
\text { repairable systems }\end{array}$ & $\begin{array}{c}\text { - Modelling maintenance costs } \\
\text { with LCC } \\
\text { - Case study }\end{array}$ \\
\hline $\begin{array}{c}\text { Lad \& } \\
\text { Kulkarni }\end{array}$ & 2012 & $\begin{array}{l}\text { Optimal maintenance } \\
\text { schedule decisions for } \\
\text { machine tools } \\
\text { considering the user's } \\
\text { cost structure } \\
\end{array}$ & $\begin{array}{l}\text { - LCC and present value are used } \\
\text { for optimal maintenance schedule } \\
\text { decisions }\end{array}$ \\
\hline
\end{tabular}

Figure 1 presents the principle for our value-based LCM. The model consists of numerical value calculations and controlling criteria, which take into account the benefits and costs of all the network members (a customer, an equipment provider, and a maintenance company). All too often, the customer evaluates the maintenance services only from the cost point of view (Barringer, 2003; Dorf, 2004; Idhammar 2009; Knights et al., 2004).

When discussing the maintenance services required by a single item (i.e. a piece of equipment, a part of equipment or a production line), there are three main options: the customer produces the services by itself (option I), the customer and the equipment provider produce the services together (option II), or an independent maintenance service company acts as an integrator and produces the services (option III). In practice, the solution is 
usually a combination of these options, which is not necessarily the most optimal way of creating value. Each member of the maintenance network examines the life-cycle profits and costs from their own viewpoint. From the customer's point of view, the main issue is planning and simulating the life cycle of the item while considering the changing market situation (variations in demand) and risks (item criticality to the production process). Thus, creating added value to the customer calls for maintenance profits during the item life cycle to be higher than the required costs. On the other hand, from the equipment provider's point of view, selling maintenance services should create added value.

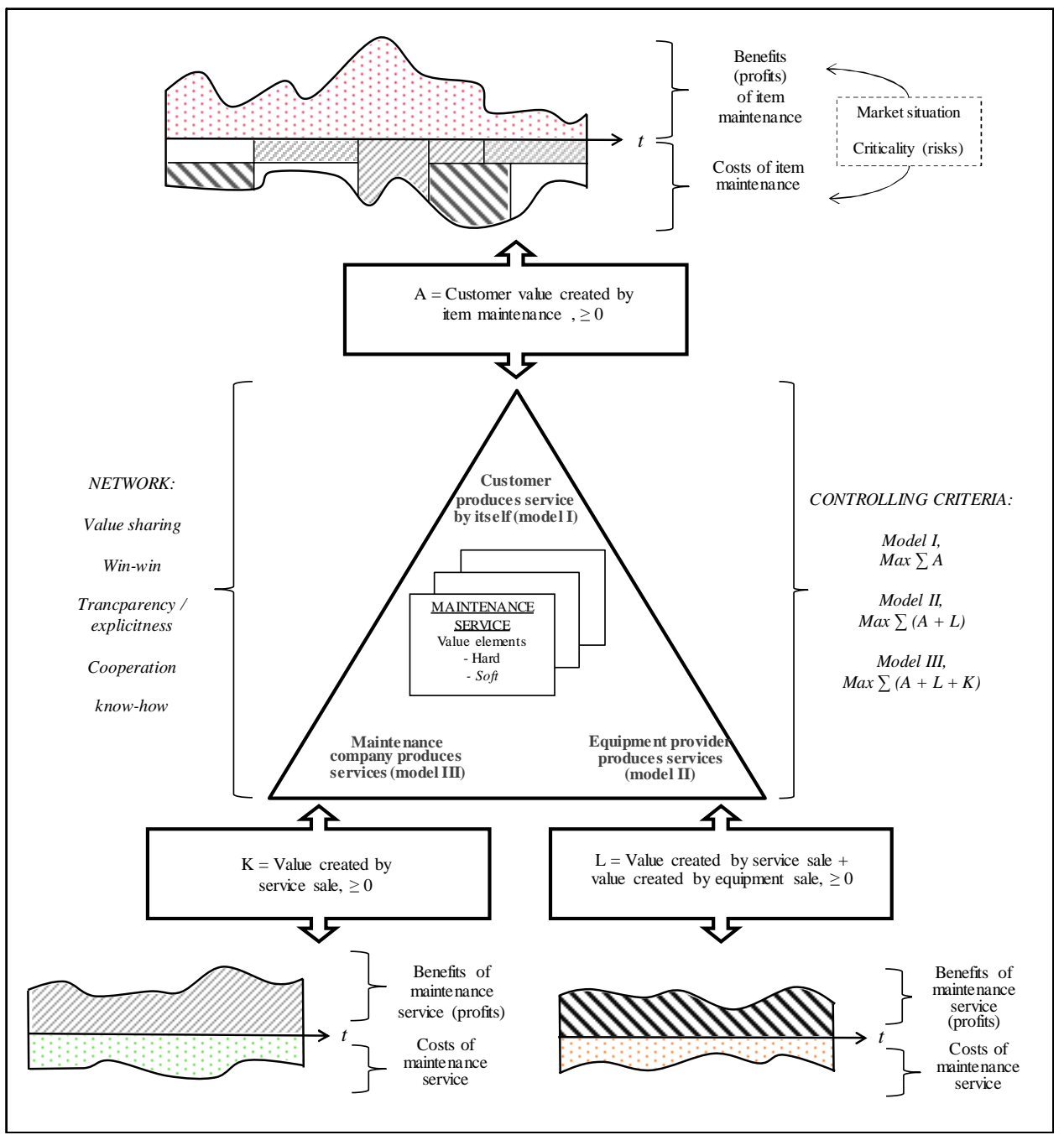

Figure 1. Value-based LCM of maintenance services 
Nowadays, the interest of equipment providers is directed not only to comprehensive maintenance services, but also to providing more and more operating services. Thus from the perspective of an equipment provider, the total present value of equipment and service sales should be positive. The independent maintenance company can be responsible for producing services on either the item level or on the level of the whole factory. The role of the maintenance company in the network is justified if the company, as an integrator, is able to create additional value for the maintenance service packages (including planning, operating and managing the maintenance). The created value should be higher than what the customer and the equipment provider can create either alone or in cooperation.

From the perspective of managing the whole network, it is a question of using life-cycle thinking to gain a better overall view of the creation of value and the distribution of the value between the various network members. Traditionally, each network member aspires to examine the created value only from their own point of view. If the customer works in close cooperation with the equipment provider, they can both create value through their own actions. However, the most interesting situation is the one in which all the network members try to create value collaboratively, using their potential know-how to improve the competitiveness of the whole network.

\section{Research design}

The group of researchers at Lappeenranta University of Technology started to develop their life-cycle model already in 2010 (Fig. 2), when they defined the cost structure of maintenance services together with a case network operating in the forest industry. The main goal of the research was to discover the most important cost categories of maintenance services from the perspective of either the service provider or the customer. These cost categories are: operating costs, subcontracting, machines and tools, spare parts, logistics, quality, environment, and other costs (Sinkkonen et al., 2013B).

The next step was to get to know the definitions and structure of value and the value creation process in the field of maintenance. Value can be seen to comprise certain value elements, which are intended to be used as an input data for the LCM. Tynninen et al. (2012) found that a 
comprehensive list of the value elements of industrial maintenance was not available, and thus they constructed preliminary lists of value elements for maintenance customers and service providers on the basis of an extensive literature review. The preliminary list of value elements was tested and improved together with industrial maintenance professionals in a workshop. The theoretical lists were further tested through a survey among the representatives of customers and service providers working in the area of maintenance. These tested lists consist of sixteen different elements, such as flexibility, availability, price, reliability, quality, contracts and relationship, etc. (Sinkkonen et al., 2013A).

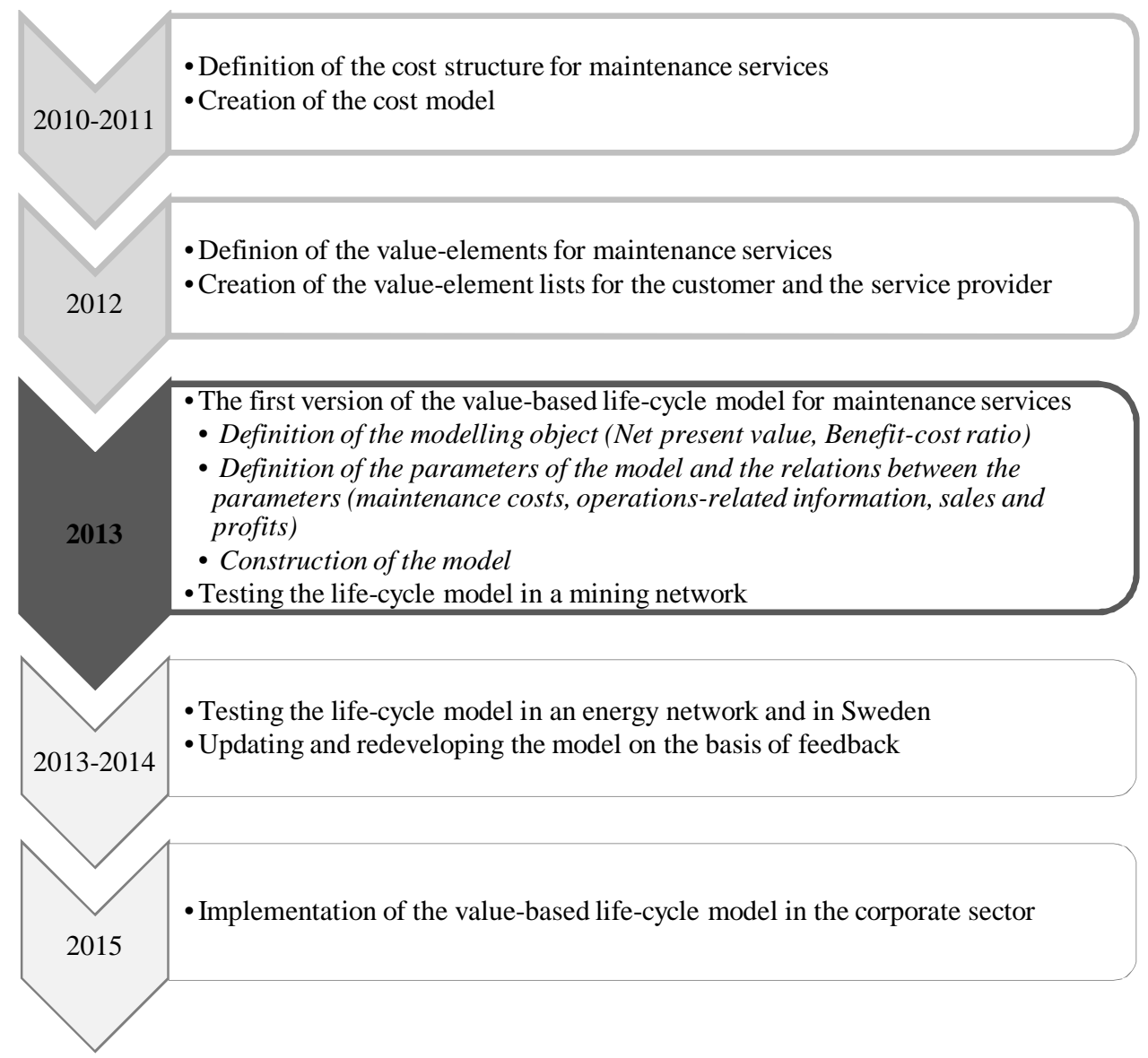

Figure 2. Development process of the value-based LCM. The current phase is highlighted in darker grey.

The value-based LCM introduced in this paper was tested with real data in case studies with two companies (a customer and a service provider) operating in a mining network. Using this received feedback from testing 
the model, the researchers have already started to improve the model towards the second version. The future versions of the model will be further tested in an energy network, and internationally in Swedish companies.

This study is a part of a large on-going project, and the case companies used in testing this model have been participating in the project closely. The companies have also their own interest in this kind of models because there is a clear need for long-term planning tools of maintenance services. (Sinkkonen et al., 2013A). Preventive maintenance has a very important role in the mining industry, and thus the failure of critical items may stop the whole process rapidly. The production equipment of the mining industry has a long life cycle, which makes it possible to get enough cost data and experiences of the maintenance services of the item to conduct research. In this case the customer and the service provider also have a long-term relationship in maintenance operations, which enables gathering experiences from both sides. In many occasions this kind of relationships does not exist, so our research environment was fruitful.

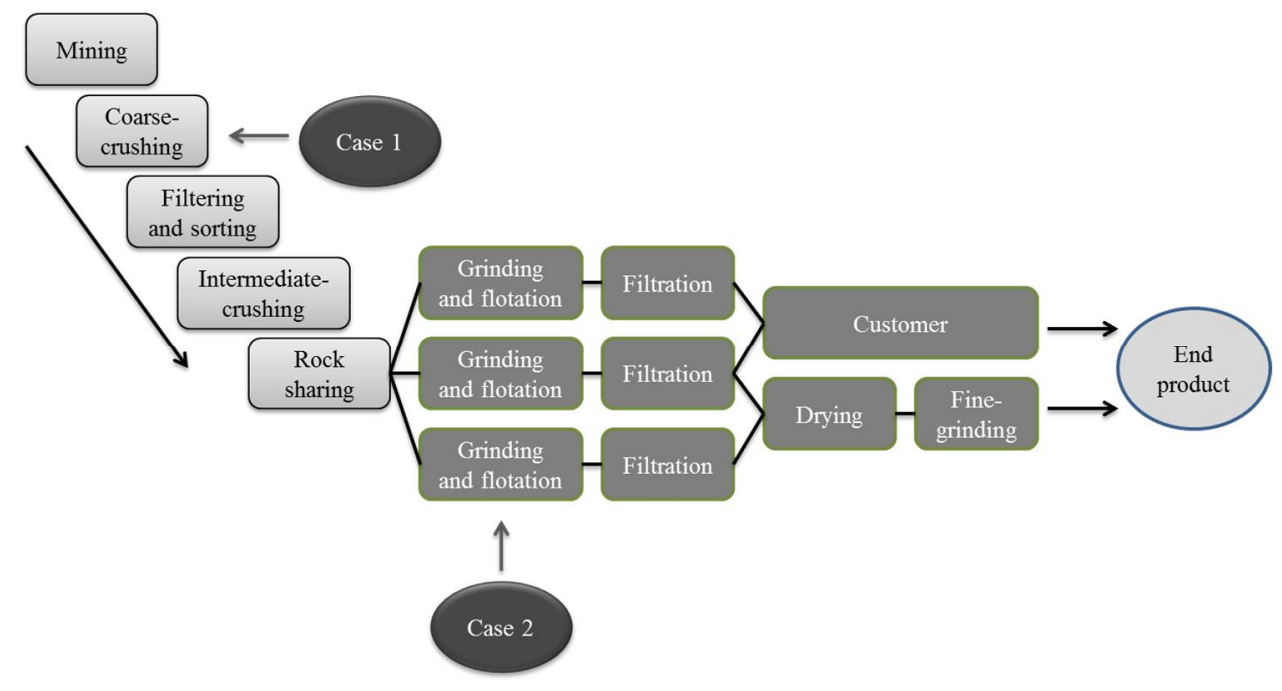

Figure 3. Case studies in relation to the mining process

The maintenance processes in the case network were addressed through a case study, because it is a useful method for testing theoretical frameworks in real-life situations. This study contains two separate cases: a jaw crusher (Case 1) and a rod mill in the grinding and flotation phase of the process (Case 2). The relation of these two cases to the mining process can be seen in figure 3 . These machines were selected in close collaboration 
with the network companies. There were not many suitable machines in the mining process to be used for testing the model, because the idea was to study also the differences between the maintenance of critical and noncritical items. Also the availability of cost data limited the number of potential cases. The jaw crusher represents a critical item in the mining process. The rod mill is not so critical, because there are in total three mills to do the grinding and flotation.

The two cases were studied through several personal interviews with the maintenance manager, head of the mining department and foreman of maintenance. After that the maintenance costs were collected by the interviewed persons using the same cost structure as in the cost model (Sinkkonen et al., 2013B). The received cost data covered from three to five history years of the preventive and corrective maintenance cost data of these two case machines. After testing the model with this data, the results were analysed together with the maintenance experts of the companies.

\section{Value-based LCM}

\subsection{Structure of the model}

The developed model is suitable for item-level decision-making situations between companies buying and selling maintenance services. The model can be used as a mutual tool on the network level or separately in each company. Practitioners will be able to use the model in planning the future, but also in monitoring the realized costs and profits from the past. This way the model can be used as a tool for both planning and monitoring. The first version of the model has been developed by using Microsoft $®$ Excel, and it consists of eight sheets. Depending on the user, these sheets include two or three input sheets and two result sheets.

The process of using the model is described in figure 4. The first two boxes represent the sheets that are common for all users. On the front page and the instruction sheet the user can explore the content and structure of the model. In addition, the use of the model is described with elucidating figures on the front page and the instruction sheet. On the initial data sheet the user can input the identification information of the item and the names of its maintenance operators. In this sheet, the user also can decide on the length of the history and planning periods for input data. In addition, the initial data -sheet allows the user to see what information is needed for the following calculation sheets and what the formal logic of 
the model is like. On this sheet, the user can also test the logic of the model and see how it works.

The LCC sheets for calculation are called the customer, service provider and equipment provider. The suppliers (service providers and equipment providers) input the maintenance costs (according to the cost categories in section 3) and sales related to the item. The customer inputs the maintenance costs as well as operations-related information (such as utilization rate, product margin and maintenance-related information) of the item on the customer sheet. The user then chooses a discounting rate which is based on the company's own targets. The discounting rate is used to calculate the net present value of past and future costs, savings and profits.

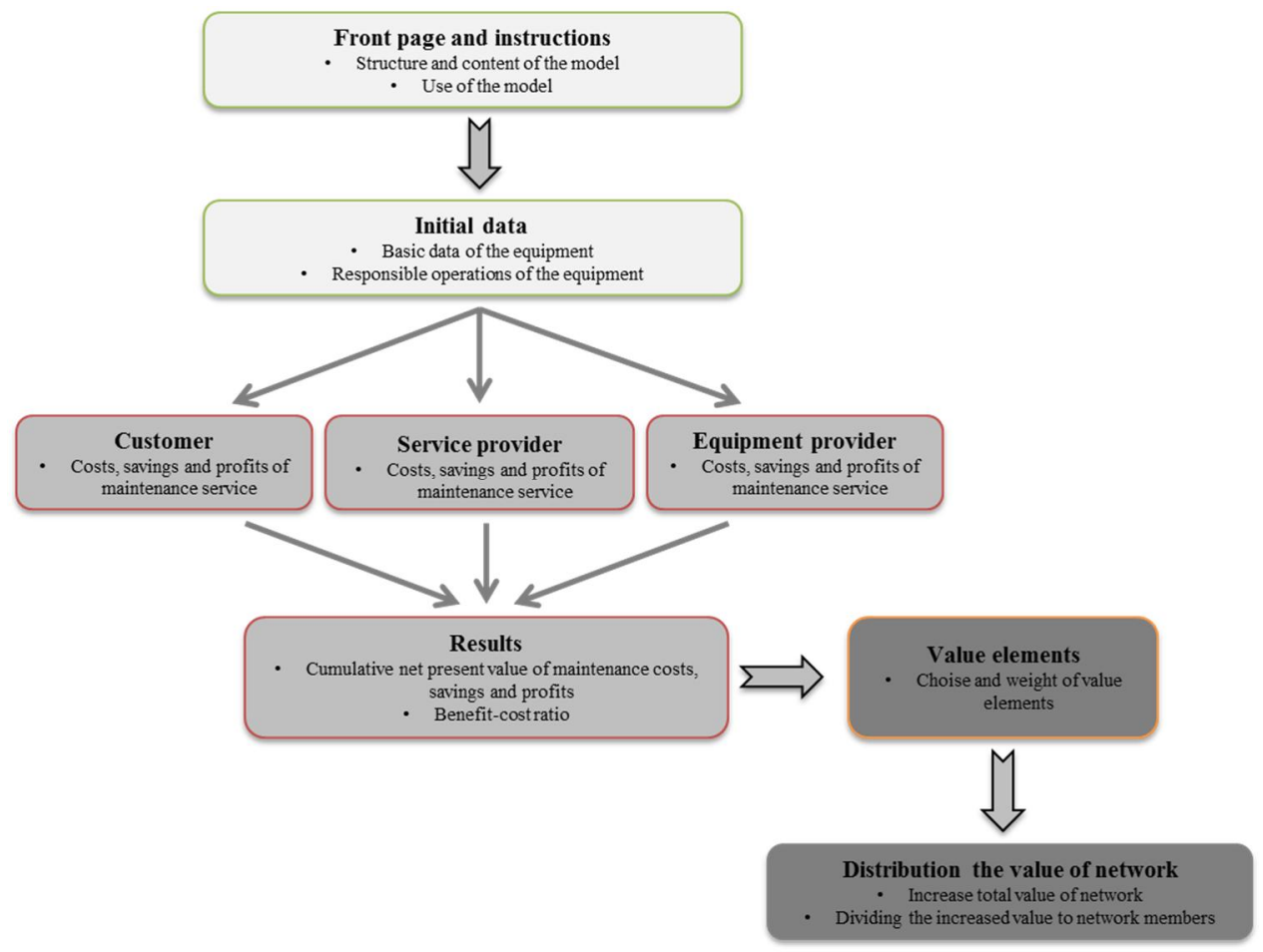

Figure 4. Structure and content of the value-based LCM

The results sheet includes the main results from the customer, service provider and equipment provider -sheets. Net present values of maintenance costs, savings and profits are presented for all network members and for each year of the history and planning period. In addition, cumulative net present values of the net profits are calculated and 
presented in this sheet. Benefit-cost ratios describe the relationship between cumulative profits and costs from each year. On the whole, the numerical value of the benefit-cost ratio should remain greater than one. This would mean that the profits are greater than the costs, and that the maintenance actions have been carried out profitably. The model also presents the main results through elucidating figures.

An important part of this model is connecting value thinking and LCC. In the value elements -sheet the user chooses one to five value elements from the element list (section 3). After that, the user weights the elements by using percentage factors based on his perspectives and thoughts. On the basis of the chosen value elements, the model divides the cumulative net profits to the weighted elements. Therefore, the model gives a numerical value to all the chosen and weighted value elements which can be seen in the distribution of the value of the network sheet. These results can be used to analyse how the gained profits and increased value can be distributed fairly to all network members.

To utilize the model for planning the future, all the results provided by the model should be considered. The benefit-cost ratio highlights the relationships between cumulative net profits and costs, while the net present values describe the cumulative profits and costs while taking the time value of money into account. In addition, the distribution the value of the network -sheet connects the value thinking and LCC. Utilizing all the above-mentioned results, the value-based LCM provides a useful tool for supporting contract negotiations and to analyse the distribution of the increased value of the network.

\subsection{Testing and results of the value-based LCM}

The value-based LCM has been mainly developed to support future planning in the maintenance network including a customer, service provider and equipment provider. However, the results presented in this paper concentrate on two players, the customer and the service provider, because the equipment provider did not have any role in the studied cases. It is also justified to test the model first with only two players for simplicity.

The model has been developed and tested with two independent cases. In this subsection we concentrate on the rod mill, which is a part of the grinding and flotation process (fig. 3). The model has also been tested with a jaw crusher case, but this case is not presented in this paper. The reason 
for this choice is that the cost data of the rod mill case was more comprehensive and clearer. In addition, the maintenance processes of the rod mill consist of both preventive and corrective maintenance actions. Testing the model was carried out with real cost data and numbers, but as requested by the case companies, the numerical results are not presented here. That is why the following figures only present simplified results without specific numerical values. The input data included cost information, operations-related information and data of preventive and corrective maintenance actions from the past five years. The input data of the future includes the same information in the next five years. The information is based on estimates and views of the future by the maintenance manager of the rod mill.

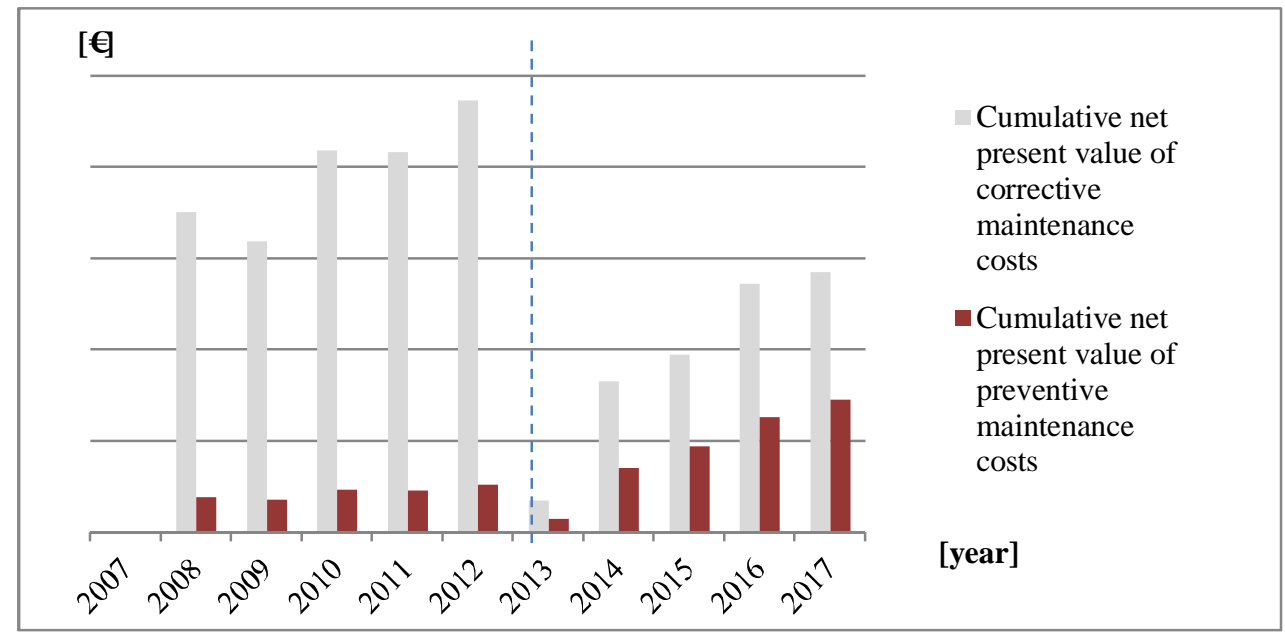

Figure 5. Cumulative net present values of customer maintenance costs

The cumulative net present values of customer maintenance costs can be seen in figure 5. During the last five years, the maintenance costs of the rod mill have mainly consisted of corrective maintenance actions. Our scenario for the future in this market situation is that the company should concentrate more on preventive maintenance actions. This way, the company will be able to improve the utilization of the device and to reach cost savings, because preventive maintenance is usually cheaper than corrective maintenance (Knights et al., 2004 and Woodward, 1997). Therefore, increasing preventive maintenance in relation to corrective maintenance, the customer company will be able to increase the total profits of equipment. However, the company will have this possibility to reach better profits only if they can utilize all the stoppages and downtime to conduct preventive maintenance. It should also be noted that the 
optimal ratio between preventive and corrective maintenance is highly dependent on the item in question, its maintenance strategy and the market situation (Pourjavad et al., 2013; Rashidi and Jenab, 2013). For example if the market situation is bad, it is not usually worthwhile to use money for preventive maintenance, because there may not be any lost profits if the machine breaks down. In these kinds of situations the financial losses might be greater if preventive maintenance is used instead of corrective maintenance. All in all, this scenario can be seen as a raising trend of preventive maintenance in figure 5.

The cumulative net present values of maintenance net profits from both the customer's and service provider's point of view can be seen in figure 6 . The past five years have been unprofitable because the operation of the item has not improved from the maintenance point of view. In addition, the share of maintenance of the maximal production time has been 10 per cent each year. In the planning period it is assumed that the investments in preventive maintenance (fig. 5) will increase the effectiveness and utilization of the device. This may enable the customer to reach better profits in the upcoming five years (fig. 6), even though there will be two big maintenance stoppages: in 2014 and 2016.

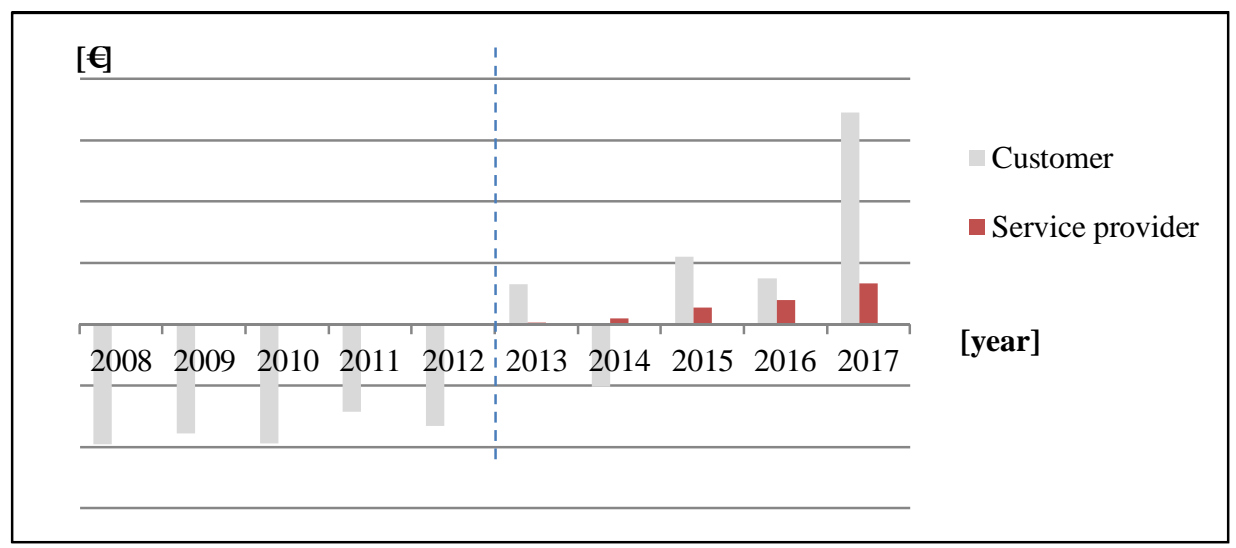

Figure 6. Cumulative net present values of maintenance from the customer's and service provider's point of view

The better profits are possible not only for the customer but also for the service provider company. The service provider will benefit from the decreasing amount of corrective maintenance, because they will then be able to plan their maintenance actions better. This way the service provider could get the better margins from maintenance operations. In addition, the maintenance operations planned in advance allow the service 
provider to use their resources more efficiently. To reach more profits, the customer and the service provider must co-operate. The plans for rod mill maintenance need to be done together, at least for two or three years forward. In long-range planning it is possible to define the needed maintenance actions for the upcoming years, and this way better reliability of the rod mill can be guaranteed.

In long-term planning, it is also important to find the optimal balance between maintenance costs and maintenance losses. Therefore, the benefit-cost ratio is a suitable indicator for analysing the balance between costs and profits. Focusing too much on optimizing the maintenance actions may lead to a situation where the costs of item maintenance are bigger than the received profits. That is why the benefit-cost ratio is a rational indicator for planning and controlling the total costs and profits of maintenance operations. In figure 7 it can be seen that the benefit-cost ratio values have been at a low level in the history period from both the customer's and service provider's point of view. As discussed before, it is assumed that the investments in preventive maintenance would increase the profits of equipment in the future. Therefore, the costs of maintenance would decrease or at least stay at the current level. Based on this, the benefit-cost ratio would increase in years 2013-2017 (fig. 7). In some years (like 2014 and 2016) the benefit-cost ratio may decrease considerably, because big maintenance actions will be carried out in these years. In figure 7 the service provider seems to have done better than the customer during the planning period because the benefit-cost ratio compares profit with costs, which are considerably smaller for the service provider than the customer.

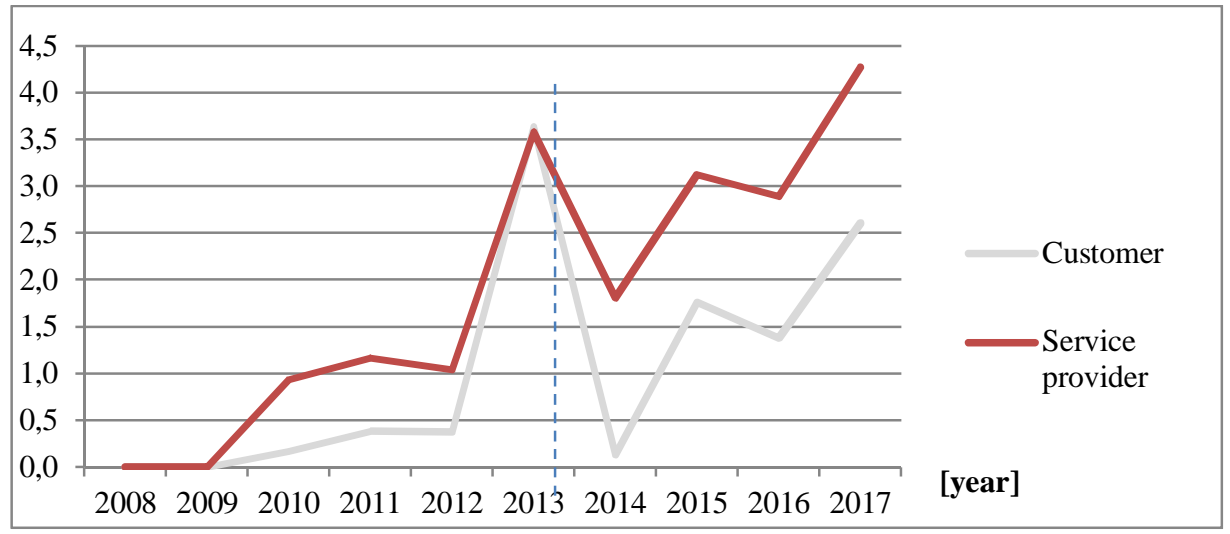

Figure 7. Benefit-cost ratio of maintenance from the customer's and service provider's point of view 
Working in a network, it is usual that the achieved profits are divided in an unfair manner among the network members. In many situations, the customer company receives most of the increased value, whereas the service provider usually gets nothing. That is why it is important to think how the increased value can be distributed fairly among all network members. For example, the customer would be able to pay some kind of a bonus to the service provider when the availability of the item stays at the agreed level. In the rod mill case, let us assume that the customer pays a 10 per cent bonus to the service provider each year during 2013-2017, which will increase the yearly profit of the service provider. However, the service provider company would still receive only 16 per cent of the total increased value of the network, whereas the customer would get 84 per cent of the increased value of the planning period (fig. 8). In this rod mill case the customer's added value, 84 per cent, has been divided into four weighted value elements, reliability, safety at work, flexibility and availability. The service provider values elements like orderliness, safety at work, flexibility and reliability. The model calculates a numerical value to each value of the elements by using the percentage factors and the added value of the whole network. This information could be useful for contracts or bonus systems between the network members.

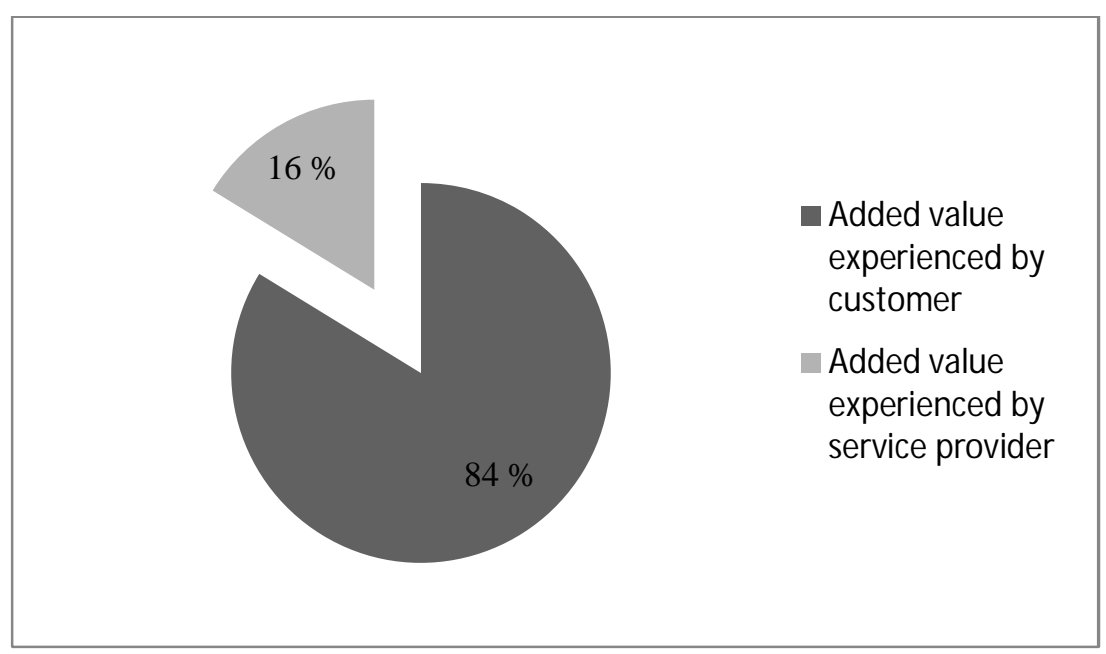

Figure 8. The growth of total value in the network

In the future, these kinds of models could be useful not only to support decision-making situations but also to analyse the distribution of increased value among the network members. 
Author

\section{Conclusions}

The purpose of this study was to create a general life-cycle model for maintenance decision making in different industries at the item level. Our first research question aimed at uncovering the structure for a model that takes the perspectives of different maintenance network members into account. Previous life-cycle models have mostly addressed the perspective of just one company, but our model connects these perspectives of different maintenance network members (customer, service provider and equipment provider) together in a new way. Each network member is able to input their own cost and profit data related to the maintenance services of one item. As a result, the model calculates the net present values of maintenance costs and profits and presents them from the points of view of all network members.

Our second research question aimed at uncovering the integration of value into the model. The user can choose one to five important value elements and weight the elements based on his perspective and thoughts in this particular maintenance service case. The model gives numerical values to the value elements, which can be then used as a basis for contracts and bonus systems between the network members.

The third research question aimed at uncovering the results generated by the model to be used in decision making. The model can be used either as a tool at the network level or separately in each company. The users can use the model for planning the future or analysing the past. This model is also suitable for small companies for building active networks to offer outsourcing services for large companies. Traditionally, each network member has considered the created value only from their own point of view. The new approach in this study is examining the value from different maintenance network members and to connect these views to improve the benefits of the whole network. In this case study we have illustrated that by using the model for the better planning of preventive and corrective maintenance, both network members (customer and service provider) could increase their profits.

Working together with the case companies convinced us that there is a real need for a long-term planning tool of maintenance services. Maintenance costs are usually a notable part of the life-cycle costs of an item, and it is important to be able to plan the future maintenance operations for the 
strategic period of the company or for the whole life-cycle period of the item.

The presented life-cycle model has been developed in process industry and it does not yet take into account different manners of production, such as batch or serial production. The model must also be tested in other lines of business than mining, before it can be called a general model. It was also noticed during the testing of the model that it was challenging to get correct and detailed cost data of the item from the companies. It was typical that maintenance costs were not available on item level, in different cost categories, or in preventive and corrective costs separately. The next step in further research will be to improve the presented model by using the feedback received from the tests. It is also important to widen the testing to cover all three network members, because the results presented in this paper concentrate on only two players, the customer and the service provider. The weight of the value elements are still based on the users' own perspectives and thoughts, but in the future the idea is to improve this part of the model. A sensitivity analysis, where the most important maintenance cost components are evaluated, is intended to include in the model. This way, companies in the maintenance network can have a way of focusing on the most relevant components of the model.This improved and expanded version of the model will be further tested in an energy network and also together with the authors' research partners in Sweden. It will be interesting to find out how the line of business, the size of the company or types of maintenance affects the value elements used in the model. It will also be interesting to find out the importance of the elements in different maintenance situations.

\section{References}

Barringer, H.P. (2003) 'A Life Cycle Cost Summary', International Conference of Maintenance Societies. May, 20-23, 2012, Perth, Australia.

Blanchard, B.S. and Fabrycky, W.J. (1998) 'Systems engineering and analysis' $3^{\text {rd }}$ edition. Upper Saddle River, New Jersey. Prentice Hall. 738 s. ISBN 0-13-135047-1.

Dorf, R.C. 2004. The Engineering Handbook, Second Edition. [web document]. In the book Fabrycky, W.J. \& Blanchard, B.S. 1991 (Eds.): Life-Cycle Cost and Economic Analysis. CRC Press. eBook ISBN 978-1-4200-3987-0. [referred 11.9.2012]. http://www.crcnetbase.com/doi/pdf/10.1201/9781420039870.ch209

Gokiene, R. (2010) 'Marginal Break Even Between Maintenance Strategies Alternatives', Engineering Economics, Vol. 21, No. 2, pp. 136-141. 
Author

Gómez, J.F., Parra, C., González, V., Crespo, A. and De León, P.M. (2008) 'Outsourcing maintenance in service providers', Joint ESREL (European Safety and Reliability) and SRA-Europe (Society for Risk Analysis Europe) Conference, September, 22-25, 2008, Valencia, Spain.

Hochschorner, E. and Noring, M. (2011) 'Practitioners'use of life cycle costing with environmental costs - a Swedish study', International Journal of Life Cycle Assessment, Vol. 16, No. 8, pp. 897-902.

Idhammar, C. (2009) 'Cut costs or improve reliability?' Pulp \& Paper International, Vol. 51 , No. 4 , pp. $27-29$.

Jun, H.K. and Kim, J.H. (2007) 'Life Cycle Cost Modeling for Railway Vehicle', International Conference on Electrical Machines and Systems, October, 8-11, 2007, Seoul, Korea.

Kayrbekoya, D., Markeset, T. and Ghodrati, B. (2011) 'Activity-based life cycle cost analysis as an alternative to conventional LCC in engineering design', International Journal of Systems Assurance Engineering and Management, Vol. 2, No. 3, pp. 218-225.

Knights, P.F., Louit, D. and Lay, A. (2004) Determining return on investment of maintenance projects using statistical cost modeling', Mining Engineering, Vol. 56, No. 8, pp. 33-39.

Korpi, E. and Ala-Risku, T. (2008) 'Life cycle costing: a review of published case studies', Managerial Auditing Journal, Vol. 23, No. 3, pp. 240-261.

Kumar, R. and Markeset, T. (2007) 'Development of performance-based service strategies for the oil and gas industry: A case study', Journal of Business and Industrial Marketing, Vol. 22, No. 4, pp. 272-280.

Lad, B. K. and Kulkarni, M.S. (2012) 'Optimal maintenance schedule decisions for machine tools considering the user's cost structure', International Journal of Production Research, Vol. 50, No. 20, pp. 5859-5871.

Lindholm, A. and Suomala, P. (2007) 'Learning by costing - Sharpening cost image through life cycle costing?', International Journal of Productivity and Performance Management, Vol. 56, No. 8, pp. 651-672.

Navarro-Galera, A. and Ortúzar Maturana, R.I. (2011) Innovating in defence policy through spending efficiency: The Life Cycle Costing Model', Journal of Policy Modeling, Vol. 33, No. 3, pp. 407-425.

Pourjavad, E., Shirouyehzad, H. and Shahin, A. (2013) 'Selecting maintenance strategy in mining industry by analytic network process and TOPSIS', International Journal of Industrial and Systems Engineering, Vol.15, No.2, pp.171 - 192

Rashidi, K. and Jenab, K. (2013) 'Intelligence-based condition monitoring model', International Journal of Industrial and Systems Engineering, Vol.13, No.2, pp.250 - 261

Sinkkonen, T., Kivimäki, H., Marttonen, S. and Kärri, T. (2013A) 'A value-based lifecycle framework for networks of industrial maintenance service', The 26th International Conference on Competitiveness Through Maintenance and Asset Management, June, 1113, 2013, Helsinki, Finland. 


\section{Title}

Sinkkonen, T., Marttonen, S., Tynninen, L. and Kärri, T. (2013B) 'Modelling costs in maintenance networks', Journal of Quality in Maintenance Engineering, Vol. 19, No. 3, pp. 330-344

Tynninen, L., Sinkkonen, T., Marttonen, S. and Ojanen, V. (2012) 'Framework for the value elements of maintenance service' The 2nd International Conference on Maintenance Performance Measurement \& Management, September, 12-13, 2012, Sunderland, UK.

Waghmode, L.Y. and Sahasrabudhe, A.D. (2012) 'Modelling maintenance and repair costs using stochastic point processes for life cycle costing of repairable systems', International Journal of Computer Integrated Manufacturing, Vol. 25, No. 4-5, pp. 353367.

Wang, Z. and Xu, X. (2009) 'SVLC: Service value life cycle model', IEEE International Conference on Cloud Computing, September, 21-25, 2009, Bangalore, India.

Woodward, D.G. (1997) Life cycle costing - theory, information acquisition and application, International Journal of Project Management. Vol.15, No. 6, pp. 335-344. 